\title{
Assessment of highly distributed power systems using an integrated simulation approach
}

G M Burt*, I M Elders, S J Galloway, N J Kelly, and R M Tumilty

Department of Electronic and Electrical Engineering, Institute for Energy and Environment, University of Strathclyde, Glasgow, $\mathrm{UK}_{\lambda}$

The manuscript was received on 19 September 2007 and was accepted after revision for publication on 16 June 2008.

DOI: 10.1243/09576509JPE535

\begin{abstract}
In a highly distributed power system (HDPS), micro renewable and low carbon technologies would make a significant contribution to the electricity supply. Further, controllable devices such as micro combined heat and power (CHP) could be used to assist in maintaining stability in addition to simply providing heat and power to dwellings. To analyse the behaviour of such a system requires the modelling of both the electrical distribution system and the coupled microgeneration devices in a realistic context.

In this paper a pragmatic approach to HDPS modelling is presented: microgeneration devices are simulated using a building simulation tool to generate time-varying power output profiles, which are then replicated and processed statistically so that they can be used as boundary conditions for a load flow simulation $\bar{\lambda}_{\boldsymbol{\lambda}}$ wich is used to explore security issues such as under and over voltage, branch thermal overloading, and reverse power flow.

Simulations of a section of real network are presented, featuring different penetrations of micro-renewables and micro-CHP within the ranges that are believed to be realistically possible by 2050 . This analysis indicates that well-designed suburban networks are likely to be able to accommodate such levels of domestic-scale generation without problems $s_{\Lambda}$ such as overloads or degradation to the quality of supply emerging.
\end{abstract}

Keywords: highly distributed power systems, simulation, load flow, thermal systems modelling

\section{BACKGROUND}

The electricity industry in the UK is under increasing legislative pressure to significantly reduce its greenhouse gas emissions and move towards a low carbon (LC) electricity supply. The Government's Energy White Papers of 2003 [1] and 2007 [2] set out aspirational carbon emissions targets of a 60 per cent reduction by 2050 and a possible strategy to achieve them. One component of this strategy is to exercise policy and regulatory measures such that the electricity system moves from relying almost exclusively on large, transmission-connected thermal power stations, and migrating towards accommodating smaller, more

\footnotetext{
*Corresponding author: Department of Electronic and Electrical Engineering, Institute for Energy and Environment, University of Strathclyde, Royal College Building, 204 George Street, Glasgow G1 1XW,UK.email:g.burt@eee.strath.ac.uk
}

environmentally sustainable forms of generation connected to distribution networks [3]. The highly distributed power system (HDPS) concept is based around the future vision that large numbers of independently owned and operated generators are connected across all voltage levels within the distribution network [4]. Similarly, the adoption of demand side management and, to a lesser extent, energy storage technologies is significantly increased. At the same time, the level of large-scale thermal capacity is reduced, as planned plant decommissioning is not fully offset by new build large-scale projects. fe.g. nuclear, clean coal, combined cycle gas turbines, or large-scale renewable developments such as offshore wind). Although the transmission infrastructure of the UK is modified to support the bulk transfer of power from remote, large-scale renewable sources, its role in supplying the total distribution demand would be diminished as the number of distributed and microgenerators increase. Within HDPS, generation 
connected to the distribution network becomes a key component of how the electricity supply system as a whole is planned, designed, and operated. The HDPS concept can be summarized by the phrase 'many loads - many sources', in contrast to the traditional 'many loads - few sources'. In order to realize this future vision for the electricity supply system, a sound understanding is required for the behaviour of distributed resources and what their impacts are across the network. This will be particularly important in planning the future network investment required to support large numbers of local generators.

Gaining a proper understanding of the behaviour of the HDPS requires the modelling of both the electricity network and the coupled microgeneration devices in a realistic operational context. However, this presents a complex engineering challenge. The phenomena that need to be accounted for span several orders of magnitude, both in terms of power ratings and the time constants associated with their dynamic response ${ }_{k}$ For example, the performance of individual power sources is of interest and detailed modelling of their performance is desirable as, ultimately, their operational characteristics will impact upon the overall operation of the HDPS. However, system performance at higher voltage levels and power flows is also of interest, but many thousands of microgenerators may be present on a section of network modelling of them all in detail would pose a significant computational challenge. To address this, a pragmatic, modular simulation approach has been developed.

The following section briefly reviews previous studies and contrasts them with the modelling approach developed in this paper ${ }^{T}$ This approach is described in detail in section 3. Section 4 applies the modelling approach to analysing the impact significant penetrations of microgeneration on a typical UK suburban electricity distribution network. The penetrations used have been defined according to different growth scenarios for microgeneration devices [5]. Section 5 summarizes the outcomes of the analysis and indicates further analysis that could be undertaken with the method described.

\section{LITERATURE REVIEW}

A number of previous studies in the pubic domain have investigated the technical issues surrounding the connection of a large number of microgenerators in a small area of network such as a new build housing development [6, 7]. These and other studies generally focused on larger distributed generation [8] and addressed key industry concerns such as: the potential increases in network fault level, quality of voltage regulation, voltage imbalance, and the breach of thermal constraints. The issues of voltage regulation and thermal constraints have been the most significant in high-voltage (HV) networks with restrictions being imposed on the amount and location of generation due to the possible failure of voltage regulation schemes when subject to varying bidirectional power flows and a lack of thermal capacity is remote rural circuits when larger scale renewable generation such as wind are connected [9].

Most studies conducted to date have been somewhat simplistic in their approach and considered the extremities of generation and demand coincidence. The occurrence of maximum local power generation and minimum demand has been widely studied due to its importance in performing the prevailing deterministic approach to network design. However, such a conservative approach to network analysis could lead to a large capital investment costs across the network that may not be wholly justifiable. It is evident from the published material that the accurate profiles for both the demand and generation are vital for understanding the true nature of network performance with microgeneration. Identifying the true level of capital investment required is an essential precursor to any widespread move towards the HDPS.

\section{MODELLING APPROACH}

To provide a more realistic assessment of likely system performance, the authors have developed a detailed, modular modelling approach to HDPS in which the performance of a representative sample of microgenerators is modelled explicitly using the ESP-r building simulation tool [10]. The outputs, sample power generation time series profiles, are then manipulated and replicated in order to create a large population of diverse devices and provide appropriate boundary conditions suitable for a network simulation.

The practicality of the approach is demonstrated through its application to the analysis of a section of typical suburban 33 and $11 \mathrm{kV}$ electricity distribution network featuring a high penetration of microgenerators, the objective being to assess any potential problems or benefits, which may result from widespread deployment of domestic-scale generation technologies, Problems (such as unacceptable voltage deviations or persistent overloading of cables) resulting from increased small-scale generation have the potential to be a significant barrier to the development of these technologies; it is thus useful to be able to make a realistic assessment of the nature of any problem in order to determine whether it can be mitigated through more intelligent operation of microgenerators, or whether network investment is required.

The following sections describe the components of the modular simulation approach in more detail. 


\subsection{Detailed device modelling using building simulation}

In the ESP-r tool, the building and its associated energy systems are represented explicitly using multiple energy-based control volumes, which are applied consistently throughout the model. In this context, a control volume is an arbitrary region of space to which conservation equations for continuity, energy (thermal and electrical), and species can be applied and one or more characteristic equations formed. As a typical building model will contain thousands of such volumes, with sets of equations extracted and grouped according to energy system. Solutions of these equations sets with real dynamic climate data, coupled with control and occupancy-related boundary conditions yields the building's time-varying energy flows over a user-defined simulation period. As the microgeneration device models are an integral part of the overall ESP-r building model [10], the power generation profiles generated using this approach incorporate the effects of climatic variation, end-user behaviour (in the case of micro combined heat and power (CHP)) and, importantly, the interaction with the building and balance of plant.

\subsubsection{CHP technologies}

The performance of micro-CHP is heavily influenced by the means of control. Most devices are heat-driven and so modelling of the dynamic building thermal load and the CHP unit thermal dynamics are essential to obtain the realistic power generation profiles.

Ferguson and Kelly [11] describe a dynamic thermal model for the combustion-based micro-CHP that can be integrated into a larger building and the balance of plant model enabling the dynamic thermal response of a device to be accurately simulated, as this has a critical influence on the temporal power output characteristics.

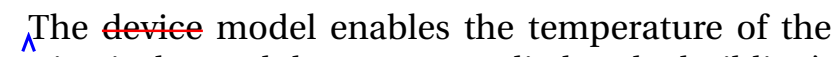
engine jacket and the water supplied to the building's heating and hot water services system to be determined along with the time-varying electrical power output. The CHP units are commonly controlled based on the thermal demand so the time-variation in key system temperatures (e.g. storage tank, heating return), calculated at each building simulation time increment will dictate when the unit produces power. This is illustrated in Fig. 1.

\subsubsection{Renewable devices}

In ESP-r, renewable devices are modelled in a similar fashion to micro-CHP devices: a control volume approach is used applied the device is an integral part of the larger building model.

3.1.2.1 Photovoltaics. ESP-r's photovoltaic (PV) device model comprises two elements: an electrical model and a thermal model, which is effectively an explicit representation of the PV device construction. Each layer of material is represented by multiple material control-volumes. The model is described in more detail by Kelly [12].

The thermal model is used to calculate the temperature of the PV in response to fluctuations in air temperature, wind speed, solar radiation data, and transient conduction through the building fabric. The electrical model calculates the electrical output of the PV device based on the prevailing solar radiation

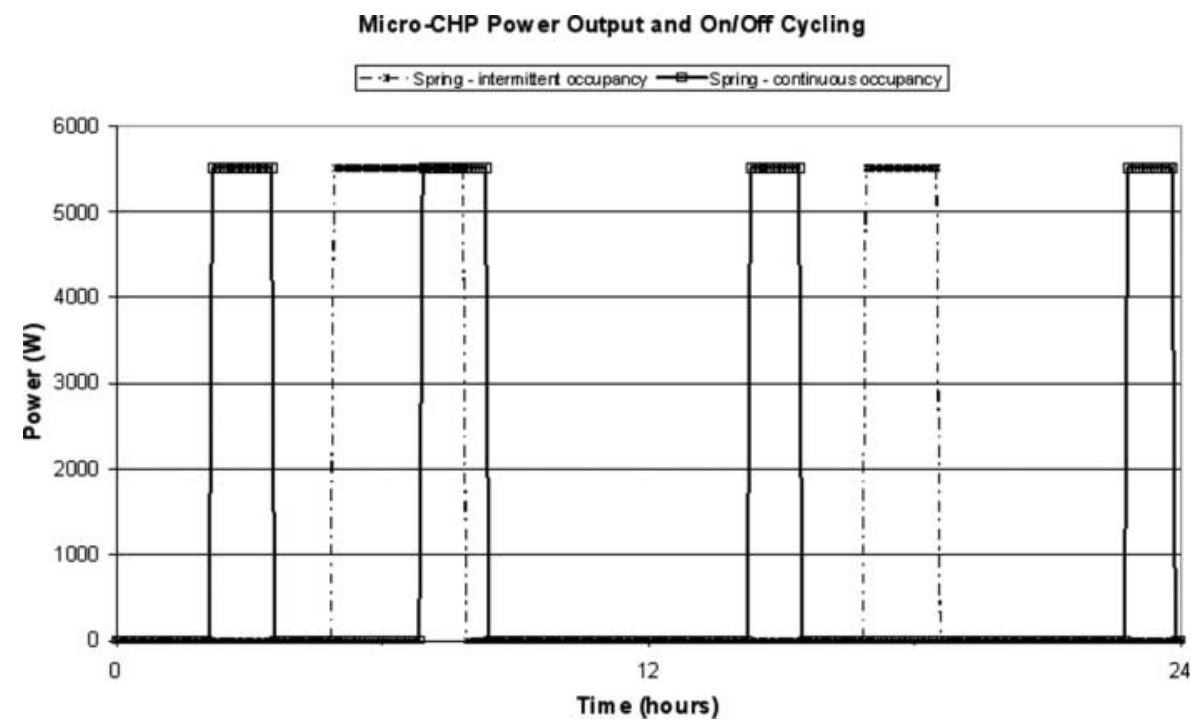

Fig. 1 Example of simulated electrical output over a typical spring day from a non-modulating $5.5 \mathrm{kWe}$ micro-CHP device in a semi-detached dwelling 


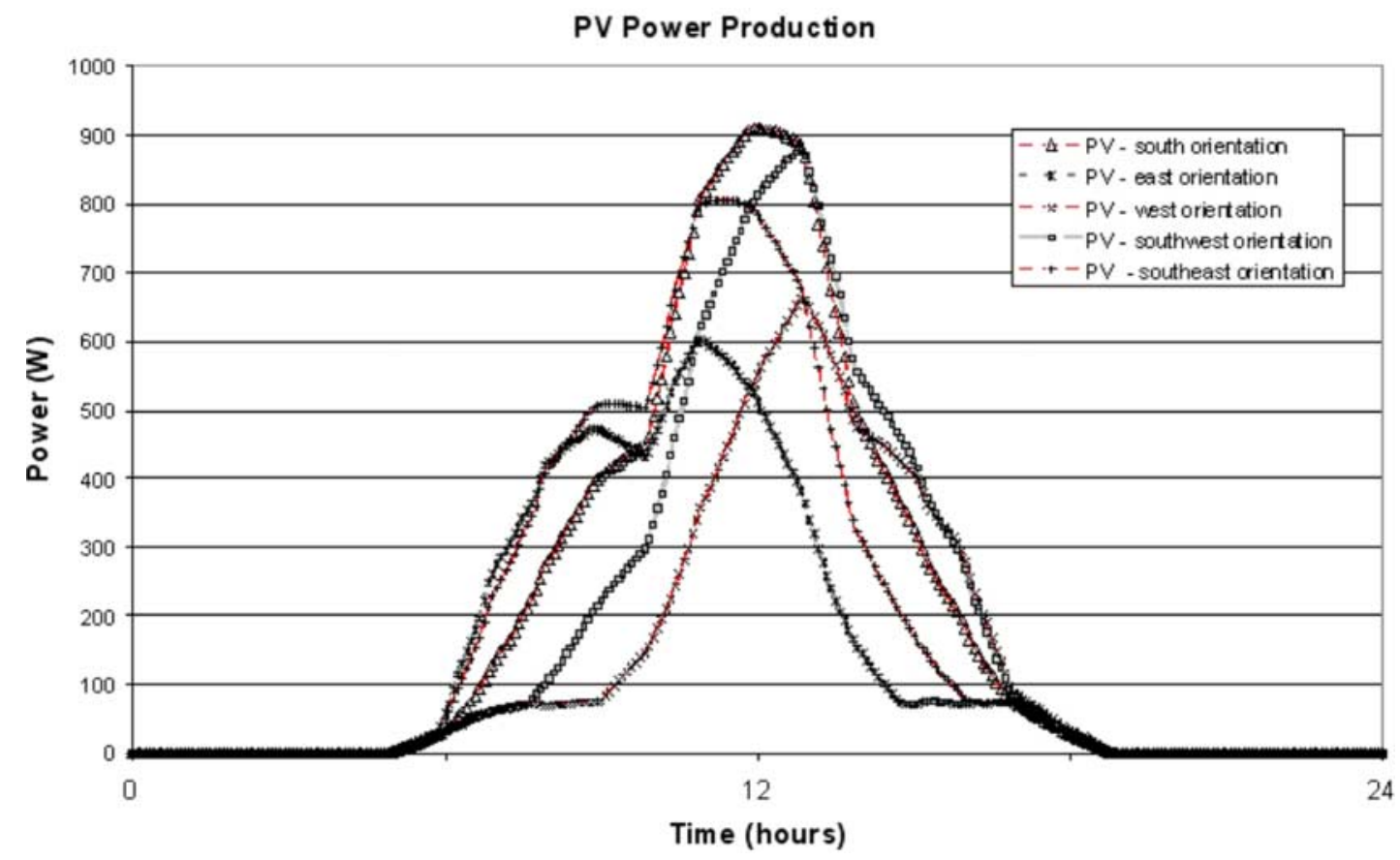

Fig. 2 Example of simulated power output from PV array mounted on a various roof orientations roof during a spring week for a Glasgow climate

levels and calculated PV temperature; both of these parameters are passed from the thermal model. Note that both models are coupled as electrical generation from the PV device slightly reduces the material temperature. Figure 2 shows the calculated electrical output from a $1.02 \mathrm{kWp}$ of crystalline silicon PV array located on the roof of a dwelling in Glasgow during a spring week.

3.1.2.2 Wind power devices. Micro wind power devices ( $\mu$-WTG) are relatively straightforward to model using building simulation tools. The model used here is based on that described by Grant and Kelly [13]. The data needed to calculate their power output fwind speed and direction ${ }_{\lambda}$ are already used as boundary conditions for the building model. The time-varying output of the wind power device is modelled using a power-coefficient-based-function. The wind data are modified in two respects to give an accurate representation of the energy yield. First, the incident wind velocity (derived from real, site-related climate data) is modified to account for the urban location of the wind turbine using a reduction factor: this effectively maps the wind profile associated with the boundary climate data (usually collected at a flat, open site) to a profile more appropriate for urban locations. Second, the data are manipulated statically to account for the effect of wind gusts on power output; these have a disproportionate impact on a small wind power device's energy yield as the power generated is pro- simulated output from a $1 \mathrm{kWp}$ (at $12.5 \mathrm{~m} / \mathrm{s}$ ) located on the roof of a dwelling in Glasgow over a week in autumn. Note that the power output achieved is significantly less than that suggested by the peak power rating (Fig. 3).

\subsection{Profile replication and manipulation}

The base case profiles are all generated at a resolution of 5 min and intrinsically contain the effects of climatic variation, geographic locality, building characteristics, and occupant behaviour. However, to generate the thousands of profiles needed to populate a detailed HDPS model would be computationally prohibitive. A more advantageous approach is to add diversity by creating variants from a base set of demand and generation profiles. This approach is illustrated for generation in Fig. 4.

For each of the three microgeneration types (CHP, $\mathrm{PV}$, and wind) base profiles are generated using ESP-r with the underlying generation profile data as summarized in Table 1.

In addition to those variables shown in Table 1, regional and geographical effects are the areas of potentially strong influence. For example, different renewable technologies will be more suited to different climatic regions. However, in this case, only a suburban location will be considered. Seasonal effects are accounted for by generating separate profiles for a summer, winter, and transition week. 


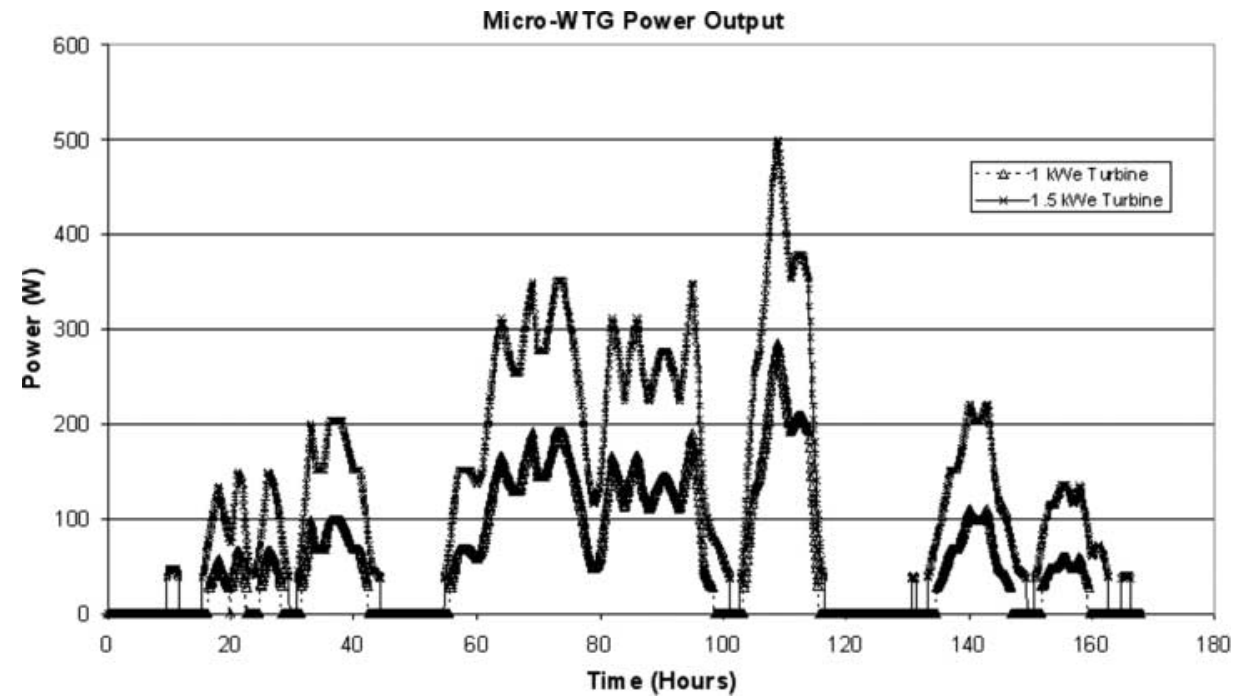

Fig. 3 Example of simulated power output from roof mounted 1 and $1.5 \mathrm{kWe}$ micro wind turbines during a spring week with a Glasgow climate

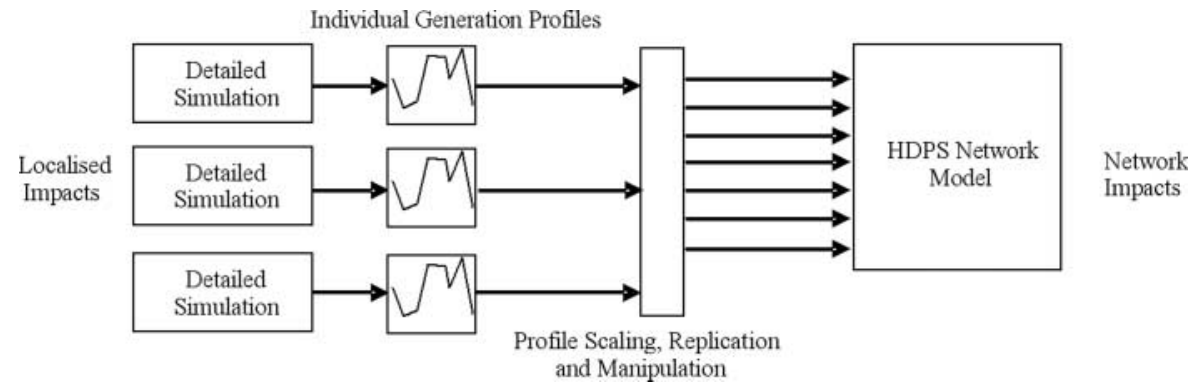

Fig. 4 HDPS modelling approach using multiple tools

Previous studies have used high/low generation output by technology type $[6,7]$ to account for diversity. Here, further diversity is added by adding vertical $(\mathrm{kW})$ and horizontal (time) variation of the base generation profiles, accounting for the effect of localized variations between microgenerators e.g. different heating control settings in different dwellings (CHP), clouds passing over the sun (PV), and turbulent wind effects ( $\mu$-WTG). Table 1 highlights the summary of variations.

All of the different combinations of generation type with dwelling type, occupancy and orientation are accounted for in the base cases, resulting in 16 different CHP profiles, 6 different PV profiles, and a further 2 different wind profiles. This gives a total of 24 base case profiles.

Table 1 Summary of underlying base generation profile context

\begin{tabular}{|c|c|c|c|c|c|c|}
\hline \multirow[b]{2}{*}{ Generation type } & \multirow[b]{2}{*}{ Rated power } & \multirow[b]{2}{*}{ Dwelling type } & \multirow[b]{2}{*}{ Occupancy } & \multirow[b]{2}{*}{ Orientation } & \multicolumn{2}{|c|}{ Variation range } \\
\hline & & & & & $(\min )$ & $(\mathrm{kW})$ \\
\hline CHP-stirling & $1.2 \mathrm{~kW}$ electrical & $\begin{array}{l}\text { Detached/semi- } \\
\text { detached }\end{array}$ & $\begin{array}{l}\text { Continuous/ } \\
\text { intermittent }\end{array}$ & $\mathrm{n} / \mathrm{a}$ & \pm 30 & $-0 \%$ \\
\hline CHP-ICE & $5.5 \mathrm{~kW}$ electrical & $\begin{array}{l}\text { Detached/semi- } \\
\text { detached }\end{array}$ & $\begin{array}{l}\text { Continuous/ } \\
\text { intermittent }\end{array}$ & $\mathrm{n} / \mathrm{a}$ & \pm 30 & $-0 \%$ \\
\hline PV & $1.02 \mathrm{~kW}$ peak & $\mathrm{n} / \mathrm{a}$ & $\mathrm{n} / \mathrm{a}$ & $\begin{array}{l}\text { East, South, } \\
\text { West, South } \\
\text { West and } \\
\text { South East }\end{array}$ & \pm 20 & $-0 \%$ \\
\hline$\mu$-WTG & $1 \mathrm{~kW}$ peak & Detached & $\mathrm{n} / \mathrm{a}$ & Roof mounted & \pm 0 & $\pm 4 \%$ \\
\hline$\mu$-WTG & $1.5 \mathrm{~kW}$ peak & Detached & $\mathrm{n} / \mathrm{a}$ & Roof mounted & \pm 0 & $\pm 4 \%$ \\
\hline
\end{tabular}


To generate a 'new' generation profile a suitable base case is selected and then a variant ereated based on user-defined variability limits. For example, if a micro wind turbine profile has limits for magnitude $(\mathrm{kW})$ and time variation of 10 per cent and $2 \mathrm{~min}$, respectively, then the profile magnitude could be varied by up to \pm 10 per cent and on/off times varied by $\pm 2 \mathrm{~min}$; the exact variation is generated based on a constrained random number with a flat probability profile across the interval defined by the limits. The resulting group of profiles can then be passed to the electrical network modelling tool (aggregated if required) as boundary conditions.

Base case demand profiles are generated for different levels of demand, termed high, medium, and low with base case data available for a full year for each of the three demand levels. In each case, a representative week for each month of the year is employed. The demand data, like the generator data, is available at 5 min sample intervals. A total of 36 base case demand profiles are available ${ }_{\wedge}$

In a similar way to that employed to generate diversity from the base generation profiles, the demand profiles are varied according to both vertical $(\mathrm{kW})$ and horizontal (time) variation against the base case. $A$ population of different demands with diversity effects in terms of the base case profile $c_{\lambda}{ }_{\lambda}$ be generated ${ }_{k}$

\subsection{Modelling the network}

The model of the electricity distribution system used to investigate the effects of microgeneration on network conditions is constructed so as to combine the goals of efficient simulation and the investigation of enough locations to be representative of the entire network. Thus, although the model extends from the interface between the $132 \mathrm{kV}$ subtransmission system to the $400 V_{\Lambda}$ low voltage bus bars, only one area of $11 \mathrm{kV}$ distribution is fully modelled in detail. All other loads and generation are represented by lumped equivalents at the appropriate locations.

The network is simulated using standard load flow analysis software - in this case the PSS/E tool [14], although others could be substituted. A balanced three-phase simulation is assumed; therefore, analysis does not extend to individual dwellings. At the most detailed level of modelling, loads and generators are aggregated at the terminals of $11 \mathrm{kV} / 400 \mathrm{~V}$ transformers. The load and generation values generated by the process described above are applied at relevant points in the network, and load flow solutions calculated for each point in time are modelled. This yields a time-series of network states, in the form of circuit power flows and bus bar voltages, which can be examined for violations of operational and statutory constraints.

\section{SIMULATIONS}

A number of authors have proposed scenarios of future circumstances in the electricity industry and in the wider energy sector for the UK (e.g. RCEP [15]; Anderson et al. [16]; and Elders et al. [17]). To illustrate the method proposed in this paper, a set of scenarios specifically considering the development of smaller-scale generation and $L G$ technologies is analysed.

\subsection{0 generation and demand scenarios}

The scenarios considered in the work reported here are based closely on those produced by the SuperGen Highly Distributed Power Systems consortium (Jardine, [5]]. Three scenarios have been developed to describe possible future situations in electricity generation and use in Great Britain for the years up to 2050, with particular focus on issues including:

(a) electricity demand and domestic energy demand;

(b) the balance between centralized and decentralized electricity generation;

(c) changes in the large centralized generation portfolio;

(d) the level of deployment of different decentralized and microgeneration technologies.

Different outcomes in each of the areas considered by the scenario, authors have been organized into a set of three scenarios, which ${ }_{\lambda}$ can be summarized as follows.

\subsubsection{Business as usuah}

This scenario envisions a future in which current trends in technological progress, environmental awareness, and policy continue to 2020. As a result, demand for electricity and domestic energy continues to grow, and large centralized generation remains much more important than decentralized plant. Although there is limited movement towards adoption of domestic-scale generation - including both micro-CHP and renewables - the domestic sector remains reliant on centralized sources for the great majority of its electricity demand.

\subsubsection{Low carbon}

The LC scenario describes a future in which environmental concerns become increasingly strong and in which carbon reduction is a priority. As a result, energy efficiency leads to a progressive reduction in electricity demand, led by the domestic sector. Decarbonization of centralized electricity generation encourages increased deployment of electric heating in new dwellings, but this is offset by significant uptake of micro-CHP and roof-top renewable technologies. 
By 2050, under this scenario, some households are net electricity exporters.

\subsubsection{Deep green}

The deep green (DG) scenario considers an alternative vision of a future in which reduction of carbon emissions is a priority. The costs of electricity generation from fossil fuels are assumed to be higher than in the LC scenario - either because of market forces or regulatory action. Therefore, in addition to complete decarbonization of centralized generation, micro-CHP technologies see less deployment as a result of higher gas prices; conversely micro wind and photovoltaic generation is more widely installed. As before, energy efficiency measures lead to a reduction in overall electricity demand, although there is an increased interest in heating domestic properties using carbon-free electricity.

These scenarios - which have been developed with reference to other energy and power studies [17] provide alternative possibilities of the conditions under which distribution systems would be required to operate. The proportions of domestic dwellings possessing the microgeneration technologies considered in this paper under each scenario is shown in Table 2.

In order to quantify the effects of the different combinations of domestic-scale generation technologies envisioned, the results of the microgeneration modelling described previously have been applied
Table 2 Percentages of UK dwellings with microgeneration by scenario type

\begin{tabular}{llrr}
\hline Generation technology & BAU & LC & DG \\
\hline Micro-CHP & $9 \%$ & $35 \%$ & $25 \%$ \\
Photovoltaic & $5 \%$ & $10 \%$ & $15 \%$ \\
Micro wind & $5 \%$ & $7 \%$ & $10 \%$ \\
\hline
\end{tabular}

to a model of a typical British suburban electricity distribution network.

\subsection{Overview of the network modelled}

The network used for this study reported is typical of that to be found within a suburban area in the UK, and is connected to the transmission system using two circuits originating at a grid supply point (GSP) with a voltage transformation of $132 / 33 \mathrm{kV}$. Nominal distribution voltages of 33, 11 , and $0.4 \mathrm{kV}$ are used with a predominately radial network topology. Circuits at $33 \mathrm{kV}$ use overhead lines, whereas the 11 and $0.4 \mathrm{kV}$ circuits are constructed using underground cables. On-load tap changers are installed on the transformers within the GSP and at primary substations $(33 / 11 \mathrm{kV})$ and off-load tap changing is possible at secondary substations $(11 / 0.433 \mathrm{kV})$. Dual supplies from different sections of the GSP bus bar are used to supply each primary substation, whereas secondary substations are supplied using a normally open loop arrangement originating at a sectionalized bus bar within a primary substation. A single line diagram is provided in Fig. 5

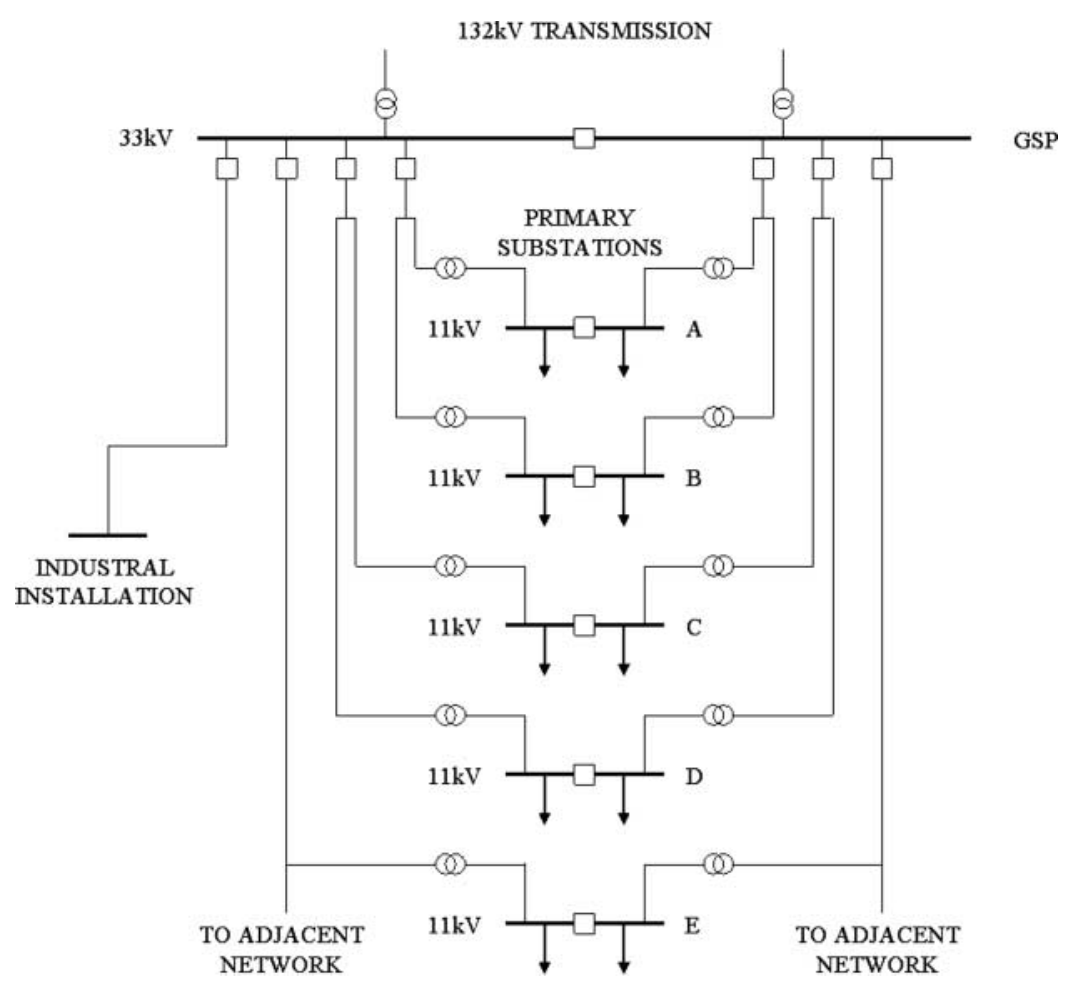

Fig. 5 Suburban electrical distribution (GSP to Primary Substation) 


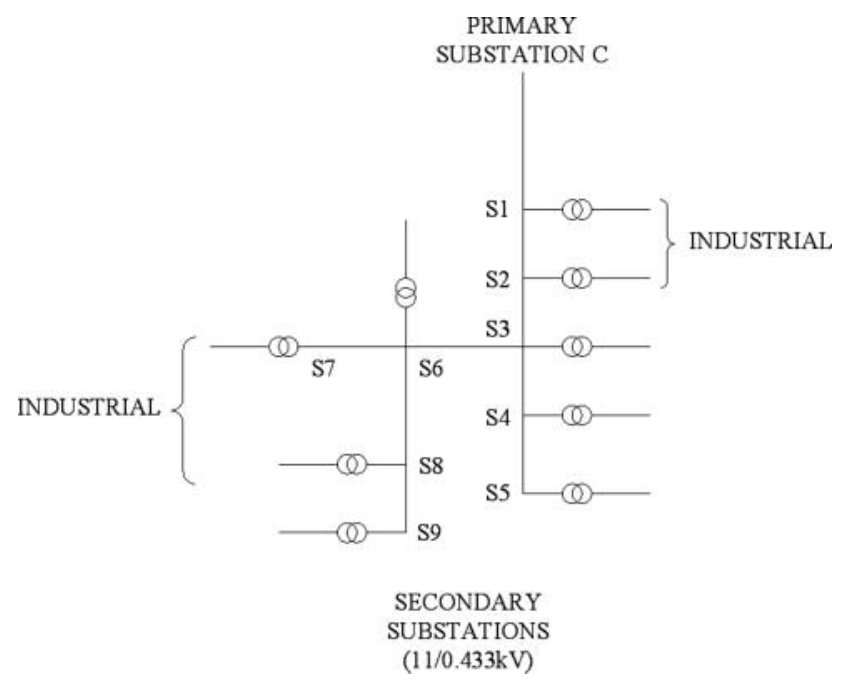

Fig. 6 Detailed $11 \mathrm{kV}$ circuit supplied from Primary Substation C

and shows the distribution from the GSP down to the primary substation level.

In order to investigate the effects of microgeneration on conditions in the $11 \mathrm{kV}$ network, one of the $11 \mathrm{kV}$ circuits fed from substation $\mathrm{C}$ is modelled in more detail, as shown in Fig. 6. The network contains a mixture of industrial and residential loads; a proportion of the residential loads are assumed to be associated with microgeneration, as discussed in the following section. Industrial loads are assumed to be constant. The remaining four $11 \mathrm{kV}$ networks are modelled as 'lumped' load and generation, representing the effects of the underlying microgeneration and load on the $33 \mathrm{kV}$ network.

\subsection{Profile generation}

The profiles generated for the modelling exercise broadly reflect the local generation mix outlined in the scenarios, featuring micro-CHP, micro wind turbines, and photovoltaics.

The base micro-CHP profiles were generated using multiple simulations of a $1.2 \mathrm{kWe}$ Stirling engine unit supplying heat and power to two different housing types: a semi-detached and detached dwelling. Further, each dwelling model was simulated with two different occupant characteristics: an intermittent

Table 3 Residential customers supplied by each secondary substation

\begin{tabular}{lccccc}
\hline & S3 & S4 & S5 & S8 & S9 \\
\hline $\begin{array}{l}\text { Number of generation } \\
\begin{array}{l}\text { customers } \\
\text { Number of demand } \\
\text { customers }\end{array}\end{array}$ & 33 & 51 & 151 & 130 & 167 \\
\hline
\end{tabular}

profile representative of a working family and a continuous profile representative of retired occupants. The models have been adapted so that their levels of insulation, and consequently their heat demand reflect with future improvements in building energy efficiency. Each building model also includes a detailed model of the heating and associated control systems.

The PV profiles were generated using the model of the detached dwelling with a $1.02 \mathrm{kWp}$ crystalline solar array attached to the roof. Multiple simulations were run with the array orientation incremented from East to West through South to account for differing roof orientations: East and West represent the extremes of what could be considered a viable PV installation.

Finally, the micro wind profiles were generated using a $1 \mathrm{kWe}$ turbine model attached to the roof of the detached dwelling.

Tables 3 and 4 provide information regarding the number of customers and the generation mix at each secondary substation.

Tables 3 and 4 are used to identify the number of each type profile that needs to be generated for the 2020 scenarios from the base generation profiles at each bus. The variation range utilized in each case is given in Table 4. A total 199 generation profiles were generated for the business as usual (BAU) scenario and 532 for the DG scenario. The proportion of households fed from each of the other $33 \mathrm{kV}$ substations having microgenerators was assumed to be the same as for substation C. Four further aggregate profiles, using the numbers of generators shown in the 'total' row of Table 4 , were produced to represent customers supplied at these locations. It should be noted that substations A, B, D, and E (Fig. 5) were assumed to supply residential customers only; no fixed industrial load element was added to the load profiles for these sites.

The aggregated demand profile at each bus utilizes the customer numbers specified in Table 3. An individual demand profile is generated (with diversity set at \pm 4 per cent $\mathrm{kW}$ only) for each customer at each bus before aggregation. The aggregated demand profile is constructed from the 18 available profiles. For example, for the 68 customers located at secendary substation $S 3$, it is assumed that there are three demand customers for each of the 18 available profiles; the remaining 14 demand customers receiving a randomly selected profile. The \pm 4 per cent range for the diversity factor is subsequently applied to each profile individually before summing to create the aggregated demand profile at secondary substation \$3.

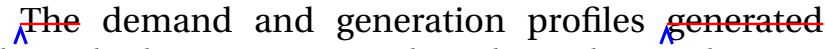
through this process are based on the application of current technologies. Over the timescales envisioned by the scenarios (up to 2050) studied, it is 
Table 4 Generation mix for each scenario at each $11 \mathrm{kV}$ substation

\begin{tabular}{|c|c|c|c|c|c|c|c|c|c|c|c|c|}
\hline & \multicolumn{4}{|c|}{ BAU 2020} & \multicolumn{4}{|c|}{ LC 2020} & \multicolumn{4}{|c|}{ DG 2020} \\
\hline & CHP & PV & Wind & No Gen & CHP & PV & Wind & No Gen & CHP & PV & Wind & No Gen \\
\hline S3 & 6 & 3 & 3 & 56 & 17 & 6 & 4 & 41 & 17 & 10 & 6 & 35 \\
\hline S4 & 9 & 5 & 5 & 85 & 26 & 10 & 7 & 61 & 26 & 15 & 10 & 53 \\
\hline S5 & 27 & 15 & 15 & 249 & 76 & 30 & 21 & 179 & 76 & 45 & 30 & 155 \\
\hline S8 & 23 & 13 & 13 & 213 & 65 & 26 & 18 & 153 & 65 & 39 & 26 & 132 \\
\hline S9 & 30 & 16 & 16 & 277 & 84 & 33 & 23 & 199 & 84 & 50 & 33 & 172 \\
\hline
\end{tabular}

possible that new devices will become available which will significantly increase the capacity of microgeneration, which-can be deployed within an individual dwelling. For example, the greater electrical efficiency of fuel-cell CHP systems [18] over the engine-based systems modelled here would require the installation of a device of greater electrical output in order to satisfy the same thermal demand. Similarly, development in renewable devices might allow a greater generation capacity to be affordably integrated into a building. To make an initial (albeit crude) assessment of the impact of such changes, the density of microgenerators was quadrupled prior to ${ }_{\lambda}$ (speculative) 2050 network simulations. Although this does not fully substitute for a detailed simulation of the operating characteristics of future devices, it does provide a rough indication of the extent of any problems or benefits derived from significantly increased penetrations of microgeneration.

The profiles generated using the process described previously were used in a total of seven network simulations. These covered a current day operating case (no microgeneration), the three 2020 scenarios, and the three 2050 simulations.

\section{RESULTS AND DISCUSSION}

Figures 7(a) and (b) and 8(a) and (b) show, respectively, voltages at selected bus bars and power flows in selected cables and transformers for the no microgeneration ${ }_{\lambda}$ case. Note that the voltages are presented as percentages of the nominal value, and that positive power flows denote energy travelling from the transmission grid towards end users.

Figure $_{\lambda} 7(\mathrm{a})$ and (b) clearly shows the daily cycle variation of voltages and power flows over the week shown. It can also be seen that power flows are exclusively from higher voltages to end-users. The industrial load manifests itself in the higher power flows in the mixed-use circuits in comparison to the purely residential supply lines. Voltages are generally slightly above the nominal values, as is normal practice in the UK. It can be seen that the substations supplying industrial load operate at a slightly higher voltage
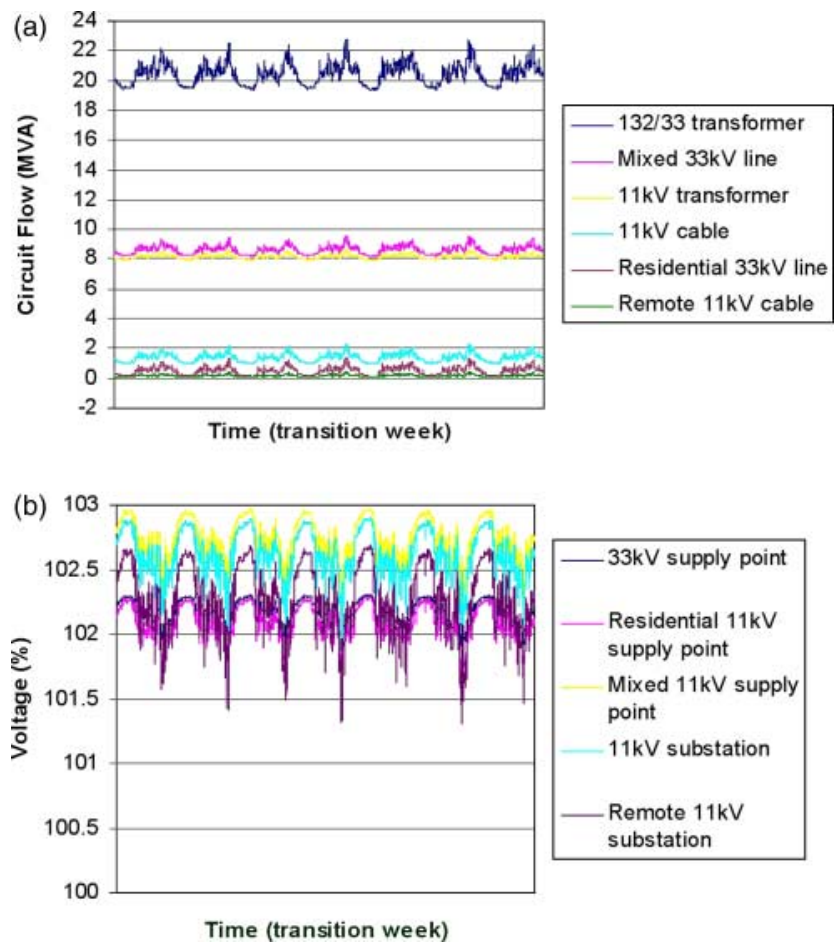

Fig. 7 (a) Selected circuit flows without microgeneration and (b) selected substation voltages without microgeneration

in order to maintain acceptable conditions at substations supplied from them, as can be seen from the lower voltage at the remote $11 \mathrm{kV}$ site.

Figures 8(a) and (b) and 9(a) and (b) show the same

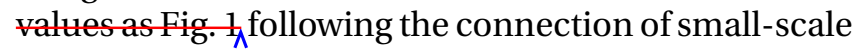
generation according to the 'BAU' and 'LC' scenarios (note: the results from the 'DG' simulation were very similar to the LC case and for brevity are not discussed here). Comparison of these results with Fig. 7(a) and (b) shows that power flows in the network are very slightly reduced by the connection of microgeneration, and that at some times of day there is a reversal of power flow in circuits serving purely residential load, so that a few tens of kilowatts are being exported from $11 \mathrm{kV}$ substations into the $33 \mathrm{kV}$ network. Study of the network voltages shows two effects. First, voltages in the mixed industrial/residential portion of the $11 \mathrm{kV}$ network have reduced significantly. This effect 

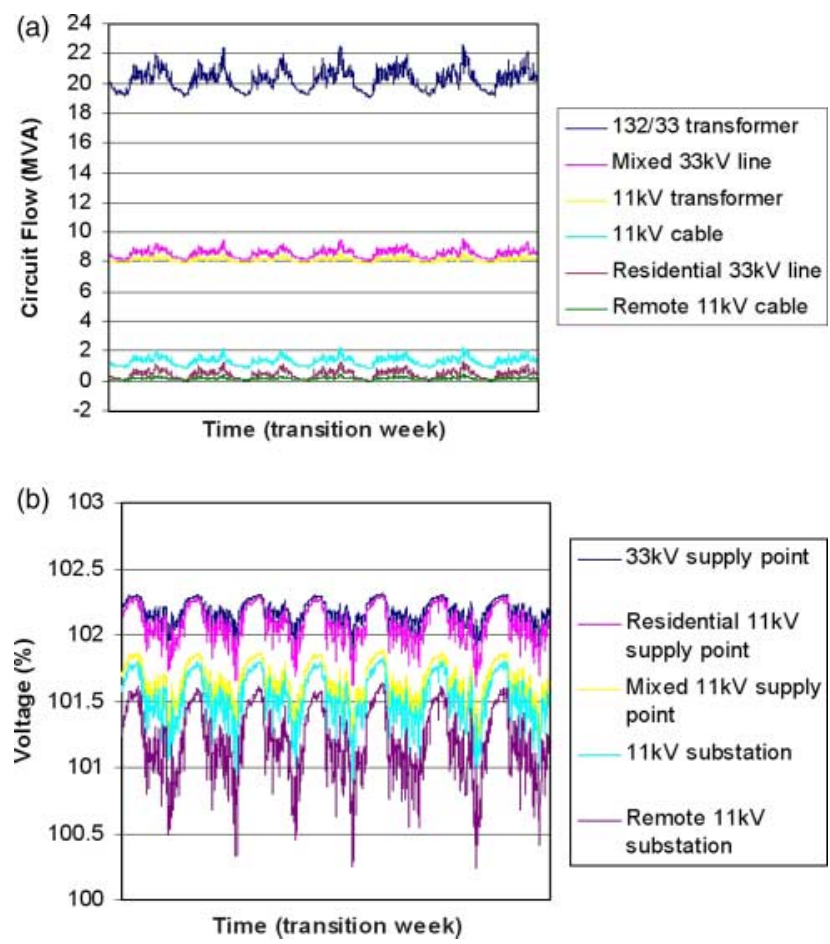

Fig. 8 (a) Selected circuit flows under 'BAU' 2020 scenario and (b) selected substation voltages under 'BAU' 2020 scenario
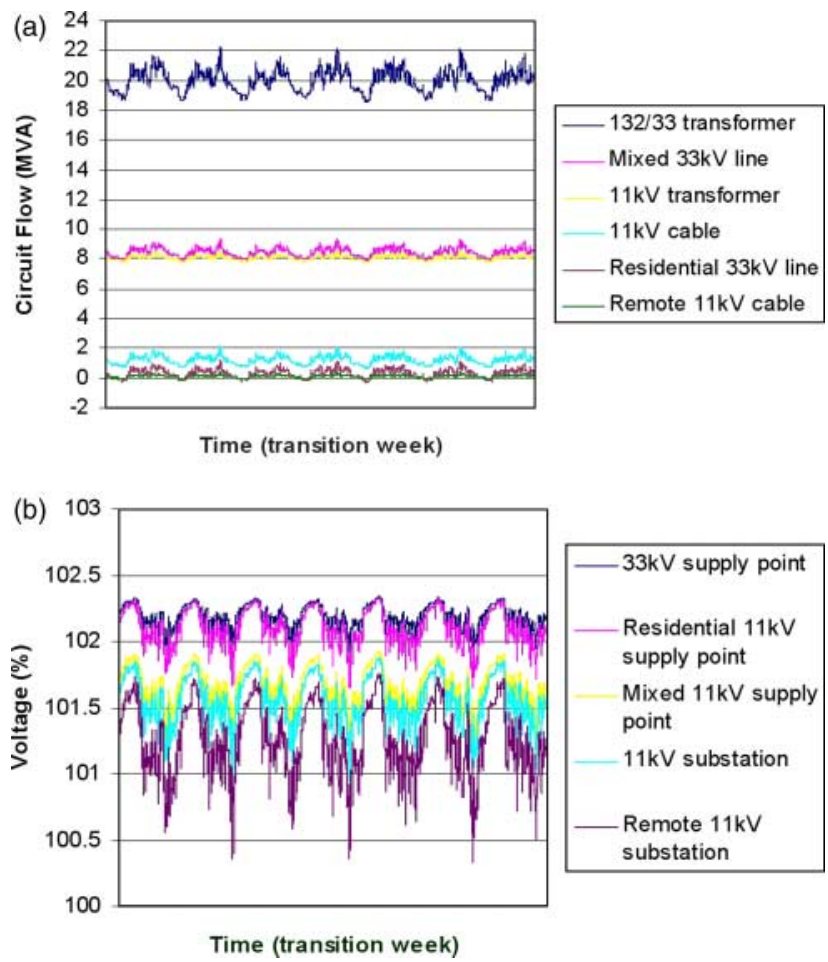

Fig. 9 (a) Selected circuit flows under 'LC' 2020 scenario and (b) selected substation voltages under 'LC' 2020 scenario arises as a result of an automated change in ratio of the $33 / 11 \mathrm{kV}$ transformer to maintain the voltage within acceptable limits. Since such ratio-changing devices tend to implement a relatively coarse control of voltage the observed change is relatively large, but takes place only once; no further changes take place as generation output varies in each scenario. Second, it can be seen that the voltage drop from the $11 \mathrm{kV}$ supply point to the remote $11 \mathrm{kV}$ substation has reduced significantly, particularly at times of peak generation. This may have implications for the correct configuration of control system to maintain acceptable voltages throughout the network. Overall, however, this analysis reveals little of serious concern for network planners and operators. However, the significant change in the voltage experienced at $11 \mathrm{kV}$ substations, which are electrically remote from the supply point suggests that further investigation of the effects of microgeneration on conditions in the low voltage network would be desirable.

Figures 10(a) and (b) and 11(a) and (b) show the results of the increasing the generation output to approximate the effects of future technological development towards 2050. As before, results for the 'BAU' and 'LC' scenarios are presented (again the 'DG' results were similar to 'LC' and are omitted for brevity). Under these scenarios, it can be seen that the trends emerging in Figs 8(a) and (b) and 9(a)
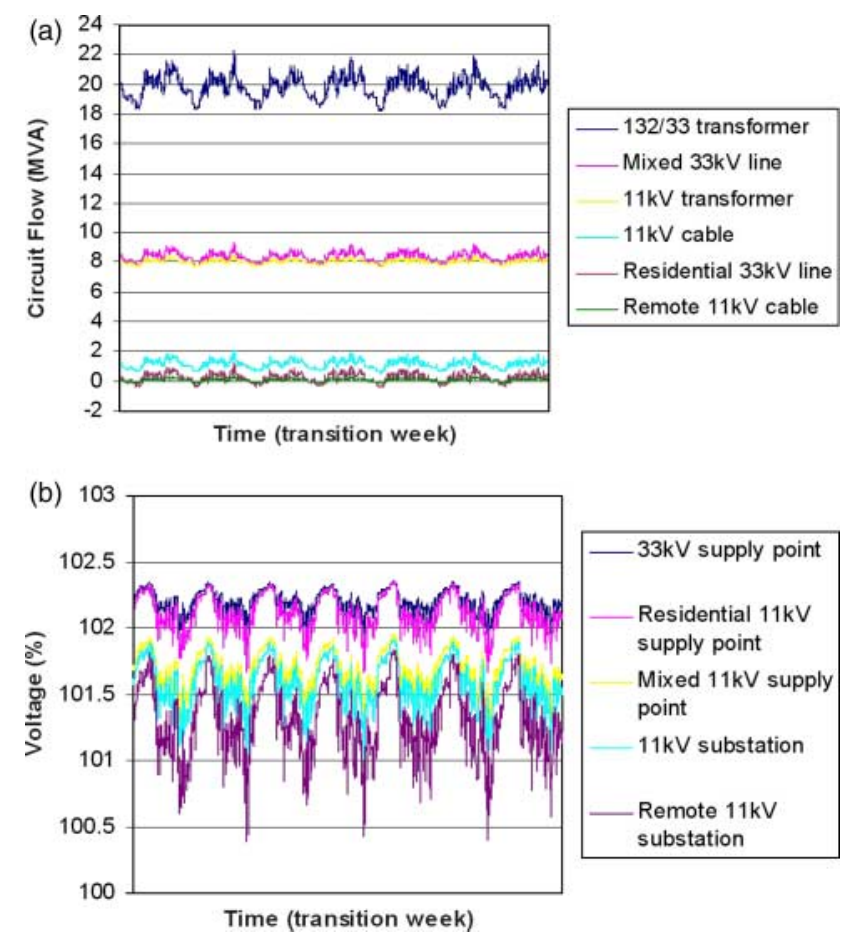

Fig. 10 (a) Selected circuit flows under 'BAU' 2050 scenario with increased generation and (b) selected substation voltages under 'BAU' 2050 scenario with increased generation 

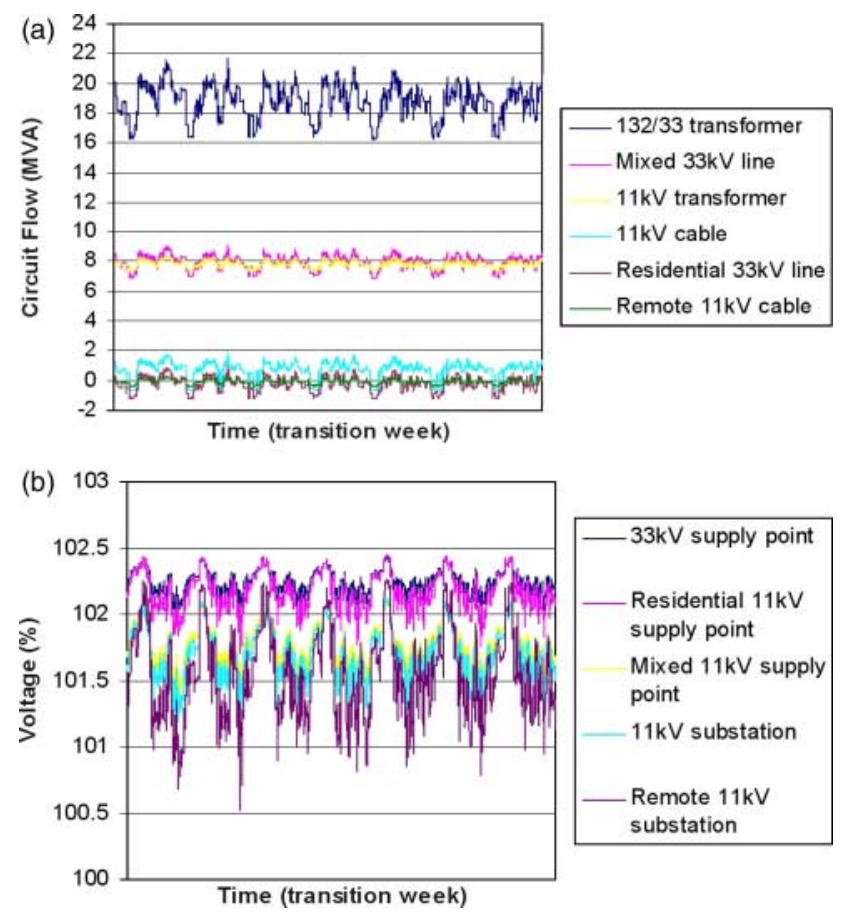

Fig. 11 (a) Selected circuit flows under 'LC' 2050 scenario with increased generation and (b) selected substation voltages under 'LC' 2050 scenario with increased generation

and (b) have become more pronounced. In particular, the increased capacity of individual microgeneration installations under the 'LC' scenario (in which investment in technological improvement in microgeneration might be expected) produces a situation in which power export from residential areas is the normal mode of network operation, as shown in Figs 11(a) and (b). Indeed the peak flows in residential network are towards the central electricity grid in this case, which may require the selection and setting of network components to be reviewed. It is noticeable also that the general rise in network voltages identified in Figs 8(a) and (b) and 9(a) and (b) has seen further increase, particularly at remote $11 \mathrm{kV}$ points. This may be indicative of more significant rises in voltages in the underlying low-voltage network to which microgeneration is connected. Further study and analysis using the techniques outlined in this paper may be desirable.

Overall, the results presented here do not identify any significant problems in the network considered as a result of the connection of reasonably foreseeable volumes of micro-CHP and micro renewable generation in residential properties. However, the study only considers a spring week, further analysis is required to assess networks behaviour in winter and summer.

It should be noted that the study does not consider wider aspects of the transition from an overwhelmingly centralized generation portfolio to a more decentralized future such as:

(a) a reduction in the volume of large central generation in operation, with consequent lessening of the rigidity with which conditions at the transmission/distribution interface are fixed;

(b) the connection to the distribution network of medium sized CHP plants associated with industrial and commercial loads;

(c) significant changes in domestic and industrial power consumption due to energy efficiency measures or migration from gas-based to electrically $y_{\Lambda}$ powered heating systems (e.g. heat pumps).

Application of similar techniques to those described in this paper to such circumstances will yield valuable further insight into network behaviour.

Control of loads and microgeneration devices is not attempted in this study; however, the effect of systems-level control on network performance could be studied using a variation of the approach described. One way to achieve this would be to replace the fixed profiles with simple profile generation models (perhaps trained using pre-simulated data) that would

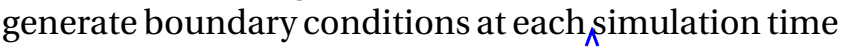
step and that could respond at any point in the simulation to a network control signal by varying the boundary conditions accordingly (i.e. shutting load $\Lambda^{\text {on or }}$ off or switching CHP on $_{\lambda}$ or eff $\widehat{\Lambda}$.

Finally, this study has concerned itself with a suburban distribution network. Such networks are inherently relatively-compact and thus are unlikely to be as susceptible to voltage variations as rural networks. Conversely, the relatively low density of suburban housing means $\lambda$ the volume of generation connected within the network may be significantly less than in an urban case. Application of the techniques described in this paper to a variety of networks - and considering also the diverse designs of distribution network in use in the UK and abroad - would yield a fuller picture of the implications of increased decentralization of electricity generation.

\section{CONCLUSIONS AND FURTHER WORK}

This paper has presented an approach to analysing the effect of increased deployment of different microgeneration technologies on electricity network. In comparison to previous studies, the method presented here analyses the likely output of microgeneration through modelling of the energy demands of and generation from individual dwellings. In addition, unlike traditional approaches to electricity network planning, which mainly consider extreme conditions such as minimum and maximum load and generation, the method described in this paper permits the 
analysis of network conditions through time so that not only the potential for problems can be identified, but their likelihood of occurrence can also be quantified. Thus, it is possible to determine whether operational problems are common enough to require costly investment in network upgrading, or whether simpler, cheaper solutions such as occasionally constraining network output will suffice.

The paper has shown the application of the analysis approach to a typical British suburban electricity network for one season of the year. Although no particular problems arising from increased microgeneration have been identified, further studies, considering, for example different periods of the year, urban and rural networks, together with examination of conditions in the low-voltage, single-phase part of the network would give a fuller picture of the impact of large-scale deployment of domestic scale generation, and permit policy in relation to its deployment and connection to the network to be better formulated.

\section{ACKNOWLEDGEMENTS}

Some of the detailed models used in this paper were undertaken as part of the International Energy Agency's Energy Conservation in Building and Community Systems research Annex 42: The Simulation of Building-Integrated Fuel Cell and Other Cogeneration Systems (www.cogen-sim.net). The Annex is an international collaborative research effort and the authors gratefully acknowledge the indirect or direct contributions of the other Annex participants.

The simulation work described in this paper was undertaken within the SuperGen Highly Distributed Power Systems consortium. The authors gratefully acknowledge the funding and support of the UK Engineering and Physical Sciences Research Council and the indirect or direct contributions of the other consortium members.

\section{REFERENCES}

1 DTI, Department for Trade and Industry. Energy white paper - creating low carbon economy. The Stationary Office, 2003a.

2 DTI, Department for Trade and Industry. Meeting the energy challenge - a white paper on energy. The Stationary Office, 2007a.

3 DTI, Department for Trade and Industry. Review of distributed generation. A Joint Government/OFGEM Report, DTI/Pub 8546/0.3k/05/07/NP, URN 07/943, The Stationary Office, $2007 \mathrm{~b}$.
4 Ackermann, T., Andersson, G., and Soder, L. Distributed generation: a definition. Electr. Power Syst. Res., 57, 195-204.

5 Jardine, C. Supergen HDPS scenarios, 2006 (Environmental Change Institute, Oxford, availble from http:// www.supergen-hdps.org/public/sg3scenarios/

6 Smart, P., Dinning, A., Maloyd, A., Causebrook, A., and Cowdroy, S. Accommodating distributed generation. Econnect project report No: 1672, prepared for: The Department of Trade and Industry, 2006.

7 Cranfield, P., Eland, J., Jackson, K., Ingram, S., and Burdon, I. Micro generation network connection. DTI Report K/EL/00295/REP, URN03/357 DTI Sustainable Energy Programme, 2003.

8 Thornycroft, J., Caisley, A., Russel, T., Willis, S., Youssef, R., Bawden, R., Holden, G., and Williams, J. Distribution system constraints and their impact on distributed generation. DG/DTI/00005/REP, May 2004.

9 Liew, S. N. and Strbac, G. Maximising penetration of wind generation in existing distribution networks. Proc. Instn Electr. Engrs. Gener. Transm. Distrib., 2002, 149(3), 256-262.

10 Clarke, J. A. Energy simulation in building design, 2nd edition, 2001 (Butterworth-Heinemann).

11 Ferguson, 嵬 and Kelly, N. J. Modelling buildingintegrated stirling CHP systems. In Proceedings of the Canadian Conference on Building Energy Simulation eSim 2006 , Vancouver, Canada, 2006, pp. 91-98.

12 Kelly, N. J. Towards a design environment for buildingintegrated energy systems: the integration of electrical power flow modelling with building simulation. $\mathrm{PhD}$ Thesis, University of Strathclyde, 1998.

13 Grant, A. D. and Kelly, N. J. A ducted wind turbine model for building simulation. Build. Services Eng. Res. Technol., 2004, 25(4), 339-350.

14 PSS/E user manual v30.0, (PTI Inc.).

15 Royal Commission on Environmental Pollution. Energy: the changing climate, 2000, (HMSO, London).

16 Anderson, K., Shackley, S., Mander, S., and Bows, A. Decarbonising the UK: energy for a climate conscious future. Tyndall Centre for Climate Change Research, 2005.

17 Elders, I., Ault, G., Galloway, S., McDonald, J., Kohler, J., Leach, M., and Lampaditou, E. Electricity network scenarios for Great Britain in 2050. In Future electricity technologies and systems, 2006 (Cambridge University Press, Cambridge, UK).

18 Hoogers, G. (Ed.) Fuel cell technology handbook, 2003, pp. 3-11-3-13 (CRC Press, London).

\section{BIBLIOGRAPHY}

Knight, I. and Ugursal, I. (Eds) Residential-cogeneration systems: a review of the current technologies. A Report of Annex 42 of the International Energy Agency Energy Conservation in Buildings and Community Systems Programme, 2005. 


\section{JPE535}

\section{Queries}

G M Burt, I M Elders, S J Galloway, N. J. Kelly, and R. M. Tumilty

Q1 References have been renumbered in order to maintain the order of citation. Please check whether all the references and their citations are same.

Q2 Figure 5 is not in its initial order of citation. Please check whether it should be removed or renumbered.

Q3 Please provide publisher's location for References 10 and 14.

Q4 Reference 'Knight and Ugursal, 2005' has been moved to bibliography section since it is not cited in the text. Please confirm whether this is correct. 